\title{
STN DBS and Suicide: \\ Is Tangential Evidence, Evidence Enough?
}

\author{
Christian Saleh
}

Paris, France

Dear Sir,

I read the article 'Suicide attempts after subthalamic nucleus stimulation for Parkinson's disease' by Rodrigues et al. [1] with great interest.

In their study the authors report on 3 retrospectively analyzed Parkinson's disease (PD) patients, with a median disease duration of 13 years, who attempted suicide after deep brain stimulation (DBS) intervention.

In the first patient the suicide attempt was reported 2 months after the DBS intervention, coinciding with a period marked by worsening marital problems.

In the second patient the suicide attempt was reported 3 months after the first DBS procedure that occurred without electrode placement due to lack of intraoperative motor benefit; a second suicide attempt by this patient was reported 13 months after the second successful DBS surgery.

In the third patient the suicide attempt was reported 15 months after the DBS intervention. The authors write, 'Our patients refused further study with postoperative cerebral MRI and our standard postoperative cerebral CT (3-mm slices) would only be merely speculative for determining the positioning of the active contacts, nevertheless the excellent motor outcome in the three referred patients is indicative of electrode location in the STN'.

Some comments are needed here:

The statement that the 'excellent motor outcome in the three referred patients is indicative of electrode location in the STN' cannot be made with such implicitness without any detailed postoperative analysis of lead position [2]. It totally ignores reports of promising clinical effects in PD patients secondary to stimulation of the region dorsal to the STN [3-6].

Furthermore, Rodrigues et al. remarkably appear not to be aware that detailed documentation of electrode location does not exclusively require MRI but can be performed perfectly on CT [7-9].

Rodrigues et al. write that 'the prevalence of suicidal ideation/suicide attempt after STN DBS has been reported as 0.3 $3 \%$...' However, none of the studies cited by Rodrigues et al. [10-12] performed a detailed postoperative documentation of the lead position to ascertain that the active contacts were actually placed in the STN.

The authors write, 'Furthermore, different active contacts were not tried, as they were consistently the contacts with best motor benefit. However, given the small volume of the STN, in patients with neuropsychological disturbs, it is unknown whether DBS selectively influences the limbic territory or exerts its influences during the current spread from an active electrode with good motor benefit within the sensorimotor STN'.

However, without knowing where the contacts were placed within the STN [13] or within the STN area [3-6] no attempt can be made to evaluate which were the most probable structures affected by the current spread from the site of implanted contacts $[14,15]$.
The authors write that 'STN-DBS patients need a closer postoperative psychiatric and behavioral follow-up'. It is surprising that the authors although placing such emphasis on STN DBS as the major potential cause of the suicide attempts make no effort to mention their surgical procedure and fail to consider altogether that the first suicide attempt in the second patient occurred in absence of any stimulation, given that no electrodes were implanted in the first place.

The authors write, 'Perhaps in patient 1 , previous marital issues had an extreme change after he gained motor independence'. What is the relationship between marital problems and motor independence in this case? Do suicidal ideation and suicide not occur as well in perfectly healthy subjects with marital problems? [16].

Is the mild temporal relation between intervention and the suicide attempt in itself evidence enough to consider STN DBS as the culprit?

\section{References}

$\longrightarrow 1$ Rodrigues AM, Rosas MJ, Gago MF, Sousa C, Fonseca R, Linhares P, Basto MA, Sousa G, Garrett C, Vaz R: Suicide attempts after subthalamic nucleus stimulation for Parkinson's disease. Eur Neurol 2010;63:176-179.

-2 Schrader B, Hamel W, Weinert D, Mehdorn HM: Documentation of electrode localization. Mov Disord 2002;17(suppl 3):S167S174.

\section{KARGER}

Fax +4161306 1234 E-Mail karger@karger.ch www.karger.com
Dr. med. Christian Saleh 25 bis, rue des Envierges FR-75020 Paris (France) Tel. +33679777656

E-Mail chs12us75010@yahoo.com 
>3 Perier C, Vila M, Feger J, Agid Y, Hirsch EC: Functional activity of zona incerta neurons is altered after nigrostriatal denervation in hemiparkinsonian rats. Exp Neurol 2000; 162:215-224.

4 Plaha P, Ben-Shlomo Y, Patel NK, Gill SS: Stimulation of the caudal zona incerta is superior to stimulation of the subthalamic nucleus in improving contralateral parkinsonism. Brain 2006;129:1732-1747.

5 Plaha P, Khan S, Gill SS: Bilateral stimulation of the caudal zona incerta nucleus for tremor control. J Neurol Neurosurg Psychiatry 2008;79:504-513.

6 Zheng Z, Zhang YQ, Li JY, Zhang XH, Zhuang P, Li YJ: Subthalamic deep brain stimulation for Parkinson's disease: correlation of active contacts and electrophysiologically mapped subthalamic nucleus. Chin Med J (Engl) 2009;122:2419-2422.

7 Pinsker MO, Herzog J, Falk D, Volkmann J, Deuschl G, Mehdorn M: Accuracy and distortion of deep brain stimulation electrodes on postoperative MRI and CT. Zentralbl Neurochir 2008;69:144-147. $\checkmark 8$ O'Gorman RL, Selway RP, Reid CJ, Hotton GR, Hall E, Jarosz JM, Polkey CE, Hill DL: Registered computed tomography images as an alternative to postimplantation magnetic resonance imaging in the assessment of subthalamic electrode placement. J Comput Assist Tomogr 2004;28:548-550.

-9 Yoshida F, Miyagi Y, Morioka T, Hashiguchi K, Murakami N, Matsumoto K, Nagata S, Sasaki T: Assessment of contact location in subthalamic stimulation for Parkinson's disease by co-registration of computed tomography images. Stereotact Funct Neurosurg 2008;86:162-166.

10 Soulas T, Gurruchaga JM, Palfi S, Cesaro P, Nguyen JP, Fenelon G: Attempted and completed suicides after subthalamic nucleus stimulation for Parkinson's disease. J Neurol Neurosurg Psychiatry 2008;79:952-954.

11 Witt K, Daniels C, Reiff J, Krack P, Volkmann J, Pinsker MO, Krause M, Tronnier V, Kloss M, Schnitzler A, Wojtecki L, Botzel K, Danek A, Hilker R, Sturm V, Kupsch A, Karner E, Deuschl G: Neuropsychological and psychiatric changes after deep brain stimulation for
Parkinson's disease: a randomised, multicentre study. Lancet Neurol 2008;7:605-614.

12 Voon V, Krack P, Lang AE, Lozano AM, Dujardin K, Schupbach M, D’Ambrosia J, Thobois S, Tamma F, Herzog J, Speelman JD, Samanta J, Kubu C, Rossignol H, Poon YY, Saint-Cyr JA, Ardouin C, Moro E: A multicentre study on suicide outcomes following subthalamic stimulation for Parkinson's disease. Brain 2008;131:2720-2728.

$>13$ Levesque JC, Parent A: GABAergic interneurons in human subthalamic nucleus. Mov Disord 2005;20:574-584.

- 14 Butson CR, Cooper SE, Henderson JM, McIntyre CC: Patient-specific analysis of the volume of tissue activated during deep brain stimulation. Neuroimage 2007;34:661-670.

15 Butson CR, Maks CB, McIntyre CC: Sources and effects of electrode impedance during deep brain stimulation. Clin Neurophysiol 2006;117:447-454.

16 Kõlves K, Ide N, De Leo D: Suicidal ideation and behaviour in the aftermath of marital separation: gender differences. J Affect Disord 2010;120:48-53.

\section{Reply}

Psychiatric disturbances in DPI after DBS are a fascinating and controversial theme. There are very few multicenter studies [1] and several case reports [2,3] on this theme. Isolated clinical reports lack consistency but add the first background hypothesis to be objectively scrutinized in larger studies.

The DBS current may spread to the nonmotor STN, limbic and associative areas. It is thus important to localize with a high degree of precision the STN and its functional subdivision into sensorimotor, associative and limbic territories. Therefore, we acknowledge that our statement 'excellent motor outcome ... is indicative of electrode location in the STN' is incomplete. A precise lead position (e.g. with thinner CT imaging slices) [4] could have been performed. Nevertheless, in practical clinical terms (intra- and postoperative) we find it very important to stress that an excellent motor response is not, in the majority of the cases, a good predictor of a correct placement of the electrode. But perhaps this excellent motor response also resulted in excessive withdrawal of levodopa therapy in our patients, which has been associated with postoperative apathy and suicide attempts [1].
We clearly state in our article that all 3 patients had attempted suicide after STN stimulation.

When seeking the etiopathogenicity and culprits of suicide attempts in DPI after DBS we usually find several reasons: either the patient was wrongly selected and psychiatric morbidity was not well documented; the lead was misplaced in a nonmotor STN subnucleus; postoperative levodopa withdrawal; postoperative behavioral red flags were undervalued by the clinician, or there are unpredictable impulsivity behaviors caused by STN-DBS [5]. In our article, we assumed and still leave open all these possibilities.

Meanwhile, as doubt prevails and while we are still researching the positioning of DBS contacts in the STN topography and its influence in cortico-subcortical circuits, the preoperative impulsivity exclusion criteria, or even the more extensive neuropsychological screening batteries trying to depict the complexity of the human mind, a practical and immediate attitude should be a closer postoperative clinical follow-up.

Margarida Rodrigues

\section{References}

$>1$ Voon V, Krack P, Lang AE, et al: A multicentre study on suicide outcomes following subthalamic stimulation for Parkinson's disease. Brain 2008;131:2720-2728.

2 Soulas T, Gurruchaga JM, Palfi S, Cesaro P, Nguyen JP, Fénelon G: Attempted and completed suicides after subthalamic nucleus stimulation for Parkinson's disease. J Neurol Neurosurg Psychiatry 2008;79:952-954.

3 Funkiewiez A, Ardouin C, Caputo E, Krack $\mathrm{P}$, Fraix V, Klinger $\mathrm{H}$, Chabardes S, Foote K, Benabid AL, Pollak P: Long term effects of bilateral subthalamic nucleus stimulation on cognitive function, mood, and behaviour in Parkinson's disease. J Neurol Neurosurg Psychiatry 2004;75:834-839.

4 Fiegele T, Feuchtner G, Sohm F, Bauer R, Anton JV, Gotwald T, Twerdy K, Eisner W: Accuracy of stereotactic electrode placement in deep brain stimulation by intraoperative computed tomography. Parkinsonism Relat Disord 2008;14:595-599.

$\checkmark 5$ Hälbig TD, Tse W, Frisina PG, Baker BR, Hollander E, Shapiro H, Tagliati M, Koller WC, Olanow CW: A multicentre study on suicide outcomes following subthalamic stimulation for Parkinson's disease. Brain 2008;131:2720-2728. 